\title{
Avoiding Sanctions at the E-Discovery Meet-And-Confer in Common Law Countries
}

\author{
Milton Luoma \\ Metropolitan State University \\ Vicki Luoma \\ Minnesota State University
}

Follow this and additional works at: https://commons.erau.edu/jdfs|

Part of the Computer Engineering Commons, Computer Law Commons, Electrical and Computer Engineering Commons, Forensic Science and Technology Commons, and the Information Security Commons

\section{Recommended Citation}

Luoma, Milton and Luoma, Vicki (2010) "Avoiding Sanctions at the E-Discovery Meet-And-Confer in Common Law Countries," Journal of Digital Forensics, Security and Law. Vol. 5 : No. 4 , Article 4. DOI: https://doi.org/10.15394/jdfsl.2010.1084 Available at: https://commons.erau.edu/jdfsl/vol5/iss4/4

This Article is brought to you for free and open access by

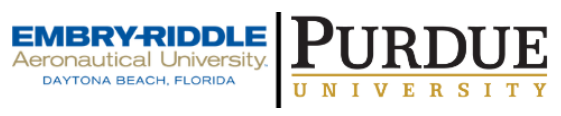
the Journals at Scholarly Commons. It has been accepted for inclusion in Journal of Digital Forensics, Security and Law by an authorized administrator of Scholarly Commons. For more information, please contact commons@erau.edu.

(c)ADFSL 


\title{
Avoiding Sanctions at the E-Discovery Meet-And- Confer in Common Law Countries
}

\author{
Milton Luoma ${ }^{1}$ and Vicki Luoma ${ }^{2}$ \\ ${ }^{1}$ Metropolitan State University \\ St. Paul, Minnesota U.S.A. \\ ${ }^{2}$ Minnesota State University \\ Mankato, Minnesota U.S.A.
}

\begin{abstract}
The rules of civil procedure in common law countries have been amended to better deal with the requirements of electronic discovery. One of the key changes in case management is the scheduling of a meet-and-confer session where the parties to litigation must meet early in the case before any discovery procedures have begun to exchange information regarding the nature, location, formats, and pertinent facts regarding custody and control of a party's electronically stored information (ESI). Failure to abide by the rules and participate in good faith at the meet-and-confer session can have dire consequences for the parties and lawyers involved. The authors discuss the importance of creating and maintaining an ESI data map as a means to demonstrate good faith and effectively comply with the requirements of the meet-and-confer.
\end{abstract}

Keywords: ESI, data map, data mapping, meet-and-confer, electronic discovery

\section{INTRODUCTION}

The advent of major changes in the rules of discovery has had a much more farreaching impact on the litigation process than anyone could foresee. The rapid increase in the volume of electronic documents has transformed the discovery process from one involving a cumbersome paper copying process to one involving huge amounts of electronic documents requiring specialised software and technical expertise to properly search for documents relevant to the issues involved in the litigation.

One of the new features in the pre-trial discovery process in common law countries is the requirement that legal counsel for all litigants meet and confer regarding the nature, location, custody and control of all electronically stored information (ESI) that may be relevant to the discovery process. This procedure is intended to be non-adversarial and is meant to facilitate the discovery process throughout the litigation. Before electronically stored information became the focus of all discovery requests, most pre-trial hearings involved meetings between 
counsel regarding settlement possibilities, establishing pre-trial deadlines for discovery, settlement conferences, and the like. The nature of the adversarial process had largely rendered these pre-trial proceedings to be perfunctory in nature and essentially more of a nuisance than anything else. These dramatic changes in pre-trial procedures caused by the nature of electronically stored information will have a major impact on the management of litigation for the foreseeable future.

This paper examines the likely impact of the changes in pre-trial procedures on important aspects of case management in litigation. Specifically, we consider the nature of the process prior to the emphasis on ESI and how the process has changed thus far as well as the likely implications for the future. Ultimately, the nature of the pre-trial process and case management in common law countries may well be at a tipping point where lawyers will have to make major changes in how they approach litigation pre-trial processes. This paper concludes with the recommendation of preparing a data map long before litigation commences in order to guarantee preparedness at the meet-and-confer.

\section{DISCOVERY PROCESS PRIOR TO THE FOCUS ON ELECTRONICALLY STORED INFORMATION}

Historically, before the emphasis on the electronic nature of discovery, pre-trial hearings including discovery conferences had been treated casually and rarely led to settlement of cases. Typically, niceties would be exchanged and the lawyers would leave, engage in discovery requests, and otherwise prepare for trial. That is largely the result of and the nature of an adversarial system. The discovery process in common law countries formally required cooperation and good faith responses to discovery requests, but it was not uncommon for many lawyers to engage in the appearance of good faith responses to discovery requests while engaging in obfuscation to protect the client. For example, if a good faith response to a discovery request would involve a "smoking gun" document, it may have been buried in the midst of thousands of pages of paper in the response requiring considerable time and effort to locate.

Common law countries have generally allowed litigants to conduct civilized discovery in a civil lawsuit for decades. That process included requiring parties to provide documents, answer questions both in written form and in person, and otherwise give each party a fair chance in litigation to find everything that might be relevant in a lawsuit was often more a game of hide-and-seek. If one party's request for documents was not skillfully worded so that it did not demand just the right documents, those documents were not produced. That factor made each litigant and their attorney so concerned about missing a crucial piece of information that document requests were very broad and seemingly requested everything imaginable that might even tangentially bear on the matters at issue. As poor as this system seemed to be it generally worked and litigation continued with the occasional motion to compel certain missing documents. In the 
electronic age where people store more and more information for longer periods of time, electronically stored information (ESI) subject to discovery can mean terabytes of data. ESI can be contained on hard drives, laptops, smart phones, memory sticks, back-up tapes, copy machines, network servers, online servers and multiple sources of each.

Depending on the country or the jurisdiction, before the new rules of civil procedure were adopted in either Australia or the United States, parties often were required to attend a meet-and-confer conference to help minimize discovery issues and to resolve potential problems proactively. However, many litigators came to these meetings only because it was obligatory. Further, because of the lack of trust and the lawyers' adversarial mindset, the meet-and-confer sessions were little more than a wink (we came) and a wave (we left). This attitude among litigators can no longer remain standard operating procedure because of the requirements of the new rules and the potential for severe sanctions if they are not followed. It is absolutely essential that counsel appear at the meet-and-confer well prepared to disclose the nature, location, custody and control of all electronically stored information (ESI) that may be relevant to the discovery process. The best prepared litigators will be able to answer that question long before the summons and complaint are served. A critical question is how to best develop a document that makes these disclosures in an efficient and timely manner.

\subsection{Meet-and-Confer in the United States}

Under the Federal Rules of Civil Procedure, parties must accept the new litigation reality that they must cooperate with one another to reveal everything about their ESI including location, type, source and format. In addition, litigators must come to the meet-and-confer understanding the nature, variety and kinds of electronic storage media involved, and how to retrieve data, the types of electronic data, the format in which the electronic data are stored, and the expense and backing up of their systems. The attorneys must also understand the type of ESI they need and the format desired from their adversary.

FRCP Rule 26 (f) requires that attorneys attend the meet-and-confer within the first 99 days of the commencement of litigation. Rule 26(a)(1) required initial disclosures, the preservation of discoverable information, and, most critically, the development of a proposed discovery plan

That means that potential litigants must be prepared for litigation long before litigation is likely. Specifically, Rule 26(f) provides the following with respect to the meet-and-confer:

(f) Conference of the Parties; Planning for Discovery

(1) Conference Timing. 
Except in a proceeding exempted from initial disclosure under Rule 26(a)(1)(B) or when the court orders otherwise, the parties must confer as soon as practicable - and in any event at least 21 days before a scheduling conference is to be held or a scheduling order is due under Rule 16(b).

(2) Conference Content; Parties' Responsibilities.

In conferring, the parties must consider the nature and basis of their claims and defenses and the possibilities for promptly settling or resolving the case; make or arrange for the disclosures required by Rule 26(a)(1); discuss any issues about preserving discoverable information; and develop a proposed discovery plan. The attorneys of record and all unrepresented parties that have appeared in the case are jointly responsible for arranging the conference, for attempting in good faith to agree on the proposed discovery plan, and for submitting to the court within 14 days after the conference a written report outlining the plan. The court may order the parties or attorneys to attend the conference in person.

\section{(3) Discovery Plan.}

A discovery plan must state the parties' views and proposals on:

(A) what changes should be made in the timing, form, or requirement for disclosures under Rule 26(a), including a statement of when initial disclosures were made or will be made;

(B) the subjects on which discovery may be needed, when discovery should be completed, and whether discovery should be conducted in phases or be limited to or focused on particular issues;

(C) any issues about disclosure or discovery of electronically stored information, including the form or forms in which it should be produced;

(D) any issues about claims of privilege or of protection as trial-preparation materials, including — if the parties agree on a procedure to assert these claims after production whether to ask the court to include their agreement in an order; 
(E) what changes should be made in the limitations on discovery imposed under these rules or by local rule, and what other limitations should be imposed; and

(F) any other orders that the court should issue under Rule 26(c) or under Rule 16(b) and (c). (Federal Rules of Civil Procedure, 2007)

Judges have been consistent in their interpretation of Rule 26(f) in stating what litigators should expect to accomplish at the meet-and-confer. In Hopson v. Mayor of Baltimore, Judge Grimm outlined litigators' expectations as follows:

At a minimum, they should discuss: the type of information technology systems in use and the persons most knowledgeable in their operation; preservation of electronically stored information that may be relevant to the litigation; the scope of the electronic records sought (i.e. e mail, voice mail, archived data, back up or disaster recovery data, laptops, personal computers, PDAs, deleted data) the format in which production will occur (will records be produced in "native" or searchable format, or image only; is metadata sought); whether the requesting party seeks to conduct any testing or sampling of the producing party's IT system; the burdens and expenses that the producing party will face based on the Rule 26(b)(2) factors, and how they may be reduced (i.e. limiting the time period for which discovery is sought, limiting the amount of hours the producing party must spend searching, compiling and reviewing electronic records, using sampling to search, rather than searching all records, shifting to the producing party some of the production costs); the amount of pre production privilege review that is reasonable for the producing party to undertake, and measures to preserve post production assertion of privilege within a reasonable time; and any protective orders or confidentiality orders that should be in place regarding who may have access to information that is produced. (Hopson v. Mayor of Baltimore, 5, 2006)

In the Covad case the litigators on both sides of the case were totally unprepared at the meet-and-confer. Neither lawyer provided information concerning their ESI data or demanded a particular format from the other party. (Covad Commc'ns Co. v. Revonet, Inc., 2008) John Faccola ruled that: “... the courts have reached the limits of their patience with having to resolve electronic discovery controversies that are expensive, time consuming and so easily avoided by the lawyers' conferring with each other on such a fundamental question as the format of their productions of electronically stored information. (Covad Commc'ns Co. v. 
Revonet, Inc., 2008)

Thus, the courts have been unambiguous in their declarations of exactly what is expected of parties and their lawyers in United States courts at the commencement of a case. Lawyers are on thin ice if they leave the resolution of basic electronic discovery issues for the judge to decide.

In yet another 2010 case, the defendant had produced over 21,000 documents but continually missed discovery deadlines and provided incomplete production of ESI. The court found that this case was complicated but the court found the time for "don’t worry, we'll get it to you" had passed. (Camesi v. Univ. of Pittsburgh Med. Ctr. , 2010) Although the court did not order sanctions at this point it ordered the parties back to the meet-and-confer. The court ordered the parties to discuss the production of ESI, reminding the parties that it had previously ordered that electronic file must be produced in a "searchable" format and the defendants must supplement production by reproducing ESI in native format, with metadata, seeking technical expertise and assistance when necessary. (Camesi v. Univ. of Pittsburgh Med. Ctr. , 2010)

One difficult issue that the meet-and-confer must attempt to resolve is how much ESI is the right amount to provide in discovery. If a party provides too much, it is considered data dumping. Providing too little can result in sanctions, and requesting too much can trigger a cost-shifting order while requesting too little can end in malpractice. In 2008, a party asked the court for cost shifting because the information requested was not reasonably accessible and provided an estimate of the cost of the search. The court denied the motion because the defendant had failed to offer evidence to back up their cost estimate, including the number of backup tapes, different methods used to store electronic information, or document retention policies. As a result the court ordered the parties to meet and confer to resolve their ESI discovery issues. (Mikron Indus., Inc. v. Hurd Windows \& Doors, Inc., 2008)

In a race and gender discrimination case brought in 2010, the court ordered attorney fees be paid by the plaintiff for their excessive discovery requests and their failure to comply with court instructions to reduce their requests. The plaintiff had requested sanctions against the defendants for failure to provide their ESI requests. The defendant argued that the plaintiff's request involved three years, 55 search terms, and 50 custodians that would produce approximately 474,456 documents for one year. (Edelen v. Campbell Soup Co., 2010)

In an employment law case in 2010, both parties requested the court to grant sanctions against the other party. The plaintiff moved to compel the defendant to provide relevant ESI when the defendant produced over 4 million documents without checking to see if any of these documents were relevant to the plaintiff's requests. The defendant countered that the plaintiff had served 208 key words which meant the search results were massive. The court refused to grant either party's request for sanctions and ordered them back to a meet-and-confer to 
resolve the discovery issues. (Trusz v. UBS Realty Investors LLC, 2010) Further, the court referred the parties to the Sedona Conference's Case for Cooperation. The Sedona Conference ${ }^{\circledR}$ is a prestigious non-partisan, non-profit, law-andpolicy think tank that provides guidance in various areas of law and in the area of ESI. (The Sedona Conference Cooperation Proclamation, 2008). The Sedona Conference found that the adversarial conduct in pre-trial discovery has become a serious burden to the judicial process. The proclamation points out the cost are not simply monetary but wasted time. (The Sedona Conference Cooperation Proclamation, 2008)

Attorneys in the United States and most common law countries are bound by ethical codes to represent their client zealously. The Sedona Conference proclamation argues that attorneys can be zealous and still cooperate to make full disclosure of ESI. Only through disclosure does an attorney further his or her client's interest in litigation. (The Sedona Conference Cooperation Proclamation, 2008)

\subsection{Meet-and-Confer in Australia}

The pattern of court decisions and rule changes and interpretation in the United States is not limited to the United States. On 29 January 2009, the Federal Court of Australia issued a revised Federal Court Practice Note No. 17 that mandated discovery of documents electronically in litigation. In addition, it indicated the expectation that litigants 'meet and confer' early on to agree upon a practical and cost-effective electronic discovery plan. Under the Australian Federal Court Rules, litigants must meet strict requirements for the retention and handling of electronically stored information and assure its availability for litigation. The rules require litigants to meet and confer prior to discovery to discuss ESI including, but not limited to, databases, text messages, videos, iPods, laptops, cell phones and servers. (Practice Note No. 17: Pre-Discovery Conference Checklist at 4.1)

This practice note requires the parties to meet and formulate a "strategy for the identification, collection, processing, analysis, review and exchange of Electronic Documents" including "those contained within databases, proprietary computer systems and other uncommon formats or repositories." (Practice Note No. 17: Pre-Discovery Conference Checklist at 4.1)

Increasingly, Australian courts are issuing severe sanctions for discovery errors. An Australian court recently struck key evidence from a plaintiff's case because it had been obtained in contravention of an agreed-upon search protocol. (Australian Securities and Investments Commission v Macdonald (No 5) , 2008)

In McCabe v. Batas an Australian woman was dying from lung cancer and sued the British American Tobacco Company (BAT). Numerous requested documents had been destroyed or missing, whereupon Judge Eames found as follows: 
"In my opinion, the process of discovery in this case was subverted by the defendant and its solicitor Clayton Utz, with the deliberate intention of denying a fair trial to the plaintiff, and the strategy to achieve that outcome was successful. It is not a strategy which the court should countenance, and it is not an outcome which, in the circumstances of this case, can now be cured so as to permit the trial to proceed on the question of liability. In my opinion, the only appropriate order is that the defense should be struck out and judgment be entered for the plaintiff, with damages to be assessed."

In other words, Judge Eames permitted the jury to consider only the amount of damages to award the plaintiff rather than considering the liability issues because a trial on the liability issues was rendered impossible. The plaintiff was awarded A $\$ 700,000$, or about US\$688,000, by a Melbourne jury. (McCabe v British American Tobacco Australia Services Ltd, 2002). Thus, failure on the part of a litigant to abide strictly by the rules established for electronic discovery can produce disastrous results for a party if it does not honour its discovery obligations.

In 2010 the Federal Court of Australia issued e-discovery rules requiring all electronic documents and emails to be produced and under the new Australian Federal Court rules, companies must meet strict requirements for the retention and handling of electronically stored information and ensure its availability for court proceedings. In addition under provision 6 provides for Discovery Plan and provision 7 provides for document management.

6. Discovery plans

6.1 Before the Court makes an order that discovery be given using documents in an electronic format, it will expect the parties to have discussed and agreed upon a practical and cost-effective discovery plan having regard to the issues in dispute and the likely number, nature and significance of the documents that might be discoverable in relation to them.

7. Document management

7.1 The Court expects the parties to meet and confer for the purpose of reaching an agreement about the protocols to be used for the electronic exchange of documents and other issues relating to efficient document management in a proceeding. 
Australian Federal Attorney-General Robert McClelland stated that unless there is cooperation of everyone involved in litigation, discovery is the biggest litigation expense. (Deare, 2009) Seamus Byrne stated that it is in a company's interest to be prepared for litigation. (Australian Securities and Investments Commission v Macdonald (No 5) , 2008)

\subsection{Meet-and-Confer in Canada}

The situation in Canada with respect to electronic discovery is no different than the situation in the United States and Australia. In Nova Scotia, Canada the courts recently implemented a discovery rule that requires parties to "make diligent efforts to become informed about relevant ESI in their control past or present and to search for, acquire and disclose all such data. ( Civil Procedure , 2010). In addition, the Province of Ontario has adopted a set of new rules that requires parties to meet and confer early to create a "discovery plan."

Further, Canada has a default provision in case the parties do not agree, they must identify "computers and storage media," as well as any "other sources," within the party's possession or control that are likely to contain relevant ESI; "perform[] all reasonable searches, including thorough keyword searches, to find relevant electronic information" on those sources; identify "persons who hold, or are likely to hold, relevant [ESI]"; and collect all relevant ESI from those persons.

In a case decided on July 7, 2010, the court confirmed that the amendments to the Rules do not negate pre-existing discovery obligations or judicial discretion. (Wahid v. Malinovski, 2010, 2010) The court pointed out that basic principles of fairness and efficiency in litigation as well as proportionality is still relevant under Rule 30.04(5) The case emphasizes the court's concerns about discovery being unduly long and costly and the rules were amended to streamline the discovery process. (Canadian Rules of Civil Procedure, 2009)

The Canada courts are making in clear that they expect counsel to solve their discovery problems in a co-operative and realistic manner. In a 2010 case Master Short, citing the new Rules of Civil Procedure, The Sedona Canada Principles, and the test for proportionality, ruled in favor of the defendant on grounds that the plaintiff could obtain sufficient documents. (Apotex, Inc v Richter Gedeon Vegyeszeti Gyar RT, 2010)

The court found that litigants must agree to a discovery plan in the Telus case decided in 2010. The defendant failed to provide information concerning data or the data availability. The court pointed out that the New Rules makes it mandatory to create a discovery plan, addresses some consequences but does not provide specific guidance to how imposition of a plan. Noting that the language of the applicable sub-sections is mandatory ("the parties to the action shall agree to a discovery plan"), Master Short turned to the issue of what occurs when the parties fail to make the directed agreement. He noted that while the new Rules 
address some of the consequences of a failure to agree on a discovery plan, including the ability of the court to refuse to grant any relief or costs, they do not provide specific guidance with respect to the imposition of a plan. (TELUS Communications Company v. Sharp, 2010) The court cited both sub-Rules 1.04(1) and (2) which provided the General Principle and Proportionality provisions of the Rules, Master Short concluded he had the authority to impose a discovery plan upon an unwilling litigant. (TELUS Communications Company v. Sharp, 2010).

The Ontario rules adopt the Sedona Canada Principles that provide for a "Discovery Plan" (Rule 29.1.03) which includes the scope of discovery, delivery time, information about the costs and method of production, and all other information that facilitate an expeditious, cost-effective discovery and ensure that the process is "proportionate" to the importance and complexity of the action. (Working Group 7 , 2010) Thus, the Canadian legal system has adopted similar rules and requirements for dealing with electronic discovery issues in litigation as those adopted in the United States and Australia.

\subsection{Meet-and-Confer in the United Kingdom}

In Practice direction 31, paragraph 8 provides:

The parties and their legal representatives must, before the first case management conference, discuss the use of technology in the management of Electronic Documents and the conduct of proceedings, in particular for the purpose of -

(1) creating lists of documents to be disclosed;

(2) giving disclosure by providing documents and information regarding documents in electronic format; and

(3) presenting documents and other material to the court at the trial.

In addition, paragraph 9 states, "The parties and their legal representatives must also, before the first case management conference, discuss the disclosure of Electronic Documents. In some cases (for example heavy and complex cases) it may be appropriate to begin discussions before proceedings are commenced." (DISCLOSURE OF ELECTRONIC DOCUMENTS, 2010) Further, this new rule provides for an Electronic Document Questionnaire that can be prepared by the parties and verified by the person signing the EDQ who must attend the first CMC and any subsequent hearing at which disclosure is likely to be considered. (DISCLOSURE OF ELECTRONIC DOCUMENTS, 2010) This new rule requires discussions between litigants and emphasizes the need for early and continuing communication between the litigants. The rule is too new for case support however, cases as early as 2008 in the United Kingdom had discussed the need for a meet-and-confer.

Leading cases in the United Kingdom indicate the emphasis the courts have 
placed on compliance with electronic discovery rules. In Digicel v. Cable and Wireless, a seminal opinion in the England and Wales High Court (Chancery Division), the court chastised the parties for failing to conduct adequate due diligence and to engage in a meaningful meet-and-confer session. The judge also found that counsel has a legal obligation to manage electronic discovery in litigation. Digicel has been cited in England and Wales holding that parties must conduct reasonable due diligence into their client's electronic systems prior to the required meet-and-confer sessions. (Digicel case Digicel (St. Lucia) Ltd v Cable \& Wireless Plc [2008] 2522, 2008). Thus, the obligations of legal counsel in the United Kingdom are clearly established with respect to disclosure and monitoring of electronic discovery.

With the amount of electronic data in the world the common law courts have come to the realization that there has to be balance between fairness in litigation and reasonableness. Judges across these common law countries, along with new rules, have set up requirements for meet-and-confer sessions with directions that parties must come prepared at those meetings. Effective advocates will use the meet-and-confer to determine their discovery needs, learn their client's policies and systems as well as determine preservation issues. (Gensler, 209)

Regardless of the trend of the courts to force the litigators to early conference and the requirement of cooperation, a recent Federal Judicial Center survey found that only about fifty percent of the survey participants discussed ESI in their meetand-confers and fewer than half of the court orders included a provision involving ESI. (Willging, 2009)

\section{THE SOLUTION: CREATING AN ESI DATA MAP}

Essentially, the data map can be characterised as a catalog that lists a party's electronic records and describes them by business unit and the location and type of storage media involved, retention and deletion policies of each unit and an explanation of any deviation from written company policies. The creation of an ESI data map can serve as the basis for an electronic discovery plan and provide a solution to the requirements of the meet-and-confer. The essential components of the data map include answers to the following questions:

- Who are the data custodians?

- Where are the computers, laptops, handheld devices, and data servers and who uses them?

- In what formats are the ESI?

- What are the data retention schedules and policies, deletion policies, backup policies, and archiving policies?

Before the actual data map is created, best practices require that a company first 
create an ESI team that includes personnel from all critical areas of the company, but most particularly inside (or outside) legal counsel, records management, IT management, digital forensic personnel (or consultants), and human resources management. (Luoma \& Luoma, 2010)As each business unit is examined and its data map created, key personnel from that department will be added to the team as required for including that department's or unit's contribution to the overall data map.

The next step after creating the data mapping team is to interview employees at the business unit or department levels to determine the answers to the above questions for that business unit. In addition to the company-maintained data and systems, a full data map must include any ESI that is used or maintained by employees on their personal computing devices. In addition to the above, the data map must also account for the possibility of recovering metadata, deleted files, swap files, and slack files that may be accessible only through the expertise of a digital forensic expert.

Typical questions that the data mapping team should ask employees of each business unit in developing the ESI data map including the following:

- What types of records do you keep?

- Are you required to maintain these records?

- Who else has copies of these records?

- Are there duplicate record holders?

- Can you explain these records? If not who can?

- How is the ESI stored?

- What format is each type of data maintained?

- How can the records be accessed?

- What are the retention policies for these records? Are they up to date?

Typical questions that the data mapping team should ask IT managers and other managers include the following:

- What types of records are maintained by the company?

- What is the company's retention and deletion policy? Is maintained?

- Are there any regulations with which the company must keep in compliance?

- Who is responsible to maintain those records?

- Are there duplicate record holders?

- Who in the company can explain these records? Testify about the 
records?

- How is the ESI stored?

- What format is each type of data maintained?

- Is the data in its Native format?

- How can the records be accessed?

- What are the retention policies for these records? Are they up to date?

When the information has been gathered, the data map will include a list of all of the systems, list of business processes, roles of all ESI users, document information flow of the company, and list of how email is used and how it is stored. This document will be critical to counsel successfully meeting the obligations imposed by the civil rules for the meet-and-confer session.

\section{CONCLUSION}

In conclusion, lawyers in the United States, Australia, the United Kingdom, Canada and other common law countries must decide either to put their adversarial mindset aside with respect to electronic discovery issues and attend the meet-and-confer totally prepared to provide relevant information or risk the possibility of courts moving toward the methods used in civil law countries where judges determine what is relevant and how much ESI will be provided based on the data requested and in proportion to the value of the case in question. While such a possibility may be remote, it behooves legal counsel to be well prepared by encouraging the preparation of a data map by their clients long before litigation commences. Not only must a data map be created, it must be kept current on a regular basis to guarantee that legal counsel will be fully prepared and in a position to comply with ESI disclosure at the meet-and-confer.

The primary purpose of the data map is to prepare the company for the meet-andconfer and to keep the party in compliance with the rules of civil procedure and case law. The data map can be presented to the opposing party and will provide a full accounting of what ESI is available, how it is stored, and determine what information is privileged. In addition, the data map will provide an excellent basis for an argument that producing some ESI that may be inaccessible and should be excluded from discovery requests if it is "not reasonably accessible because of undue burden or cost.”

Finally, preparing a data map can protect a party under the safe harbor provisions of Rule 37(e) in the United States and similar rules in the other common law countries to provide a basis for a party's good faith effort to comply with the rules. The preparation and maintenance of the data map as a critical component for the meet-and-confer session also underscores the critical need for lawyers to relinquish some of the control they have had over the discovery process in litigation. The need for technical expertise in the preparation and maintenance of 
ESI data maps, along with the need for technical expertise in developing appropriate search criteria in analyzing the adverse party's ESI, indicates the necessity of a team approach for effective electronic discovery plans.

\section{REFERENCES}

Civil Procedure, Rule 15.02(1)(a (Nova Scotia 2010).

Digicel case Digicel (St. Lucia) Ltd v Cable \& Wireless Plc [2008] 2522, 2522 (EWHC 2008).

DISCLOSURE OF ELECTRONIC DOCUMENTS, PRACTICE DIRECTION 31B (Oct 2010).

Apotex, Inc v Richter Gedeon Vegyeszeti Gyar RT, No 2718 (O.J. 2010).

Australian Securities and Investments Commission v Macdonald (No 5) , 1169 (NSWSC Nov 4, 2008).

Camesi v. Univ. of Pittsburgh Med. Ctr. , 2010 WL 2104639 (W.D.PA May 24, 2010).

Canadian Rules of Civil Procedure, Rule 30.04(5) para 6 (November 25, 2009).

Covad Commc'ns Co. v. Revonet, Inc., 254 F.R.D. 147, 151 (D.D.C. 2008).

Deare, K. (2009, March 3). End of the Paper Chase: Federal Court unviels Ediscovery Ryles. Australia.

Edelen v. Campbell Soup Co., WL 774186 (N.D.GA March 2, 2010).

Federal Rules of Civil Procedure, Rule 26 (f) (2007).

Gensler, S. (209). Electronic Discovery Issue: Article: Some Thoughts on the Lawyer's E-volving Duties in Discovery. N. Kentucky Law Rev , 521 -526.

Hopson v. Mayor of Baltimore, 5, 232 F.R.D. 228, 24 (D. MD 2006).

Luoma, M., \& Luoma, V. (2010). Data Maps: A Best Practice for the Meetand-Confer. Proceedings of the 2010 International Conference on E-Business, Management, and Economics. Hong Kong.

McCabe v British American Tobacco Australia Services Ltd, 73 (Unreported) (VSC March 2002).

Mikron Indus., Inc. v. Hurd Windows \& Doors, Inc., WL 1805727 (W.D. Wash April 21, 2008).

Practice Note No. 17: Pre-Discovery Conference Checklist at 4.1. (n.d.). Retrieved September 5, 2010, from http://www.fedcourt.gov.au/pdfsrtfs_p/Practice_Note_No_17_Pre-

Discovery_Conf_Checklist.pdf

TELUS Communications Company v. Sharp, 2878 (CanLII) (ONSC 2010). 
The Sedona Conference Cooperation Proclamation. (2008). The Sedona Conference Working Group Series , 1-12.

Trusz v. UBS Realty Investors LLC, WL 3583064 (D.Conn September 7, 2010).

Wahid v. Malinovski, 2010, 2010,3249 (ONSC CanLII July 7, 2010).

Willging, E. G. (2009). ed Judicial L CTR., Case-Based Civil Rules Survey: Preliminary Report To The Judicial Conference E Advisory Committee On Civil Rules 15.

Working Group 7 . (2010). The Sedona Canada Commentary on Proportionality in Electronic Disclosure and Discovery. Sedona Conference Working Group , 1-40. 
Journal of Digital Forensics, Security and Law, Vol. 5(4) 